This item was submitted to Loughborough's Research Repository by the author.

Items in Figshare are protected by copyright, with all rights reserved, unless otherwise indicated.

\title{
Damage in adhesively bonded CFRP joints : sinusoidal and impact-fatigue
}

PLEASE CITE THE PUBLISHED VERSION

PUBLISHER

(C) Elsevier

LICENCE

CC BY-NC-ND 4.0

\section{REPOSITORY RECORD}

Casas-Rodriguez, Juan P., lan A. Ashcroft, and Vadim V. Silberschmidt. 2019. "Damage in Adhesively Bonded CFRP Joints : Sinusoidal and Impact-fatigue”. figshare. https://hdl.handle.net/2134/3748. 
This item was submitted to Loughborough's Institutional Repository (https://dspace.lboro.ac.uk/) by the author and is made available under the following Creative Commons Licence conditions.

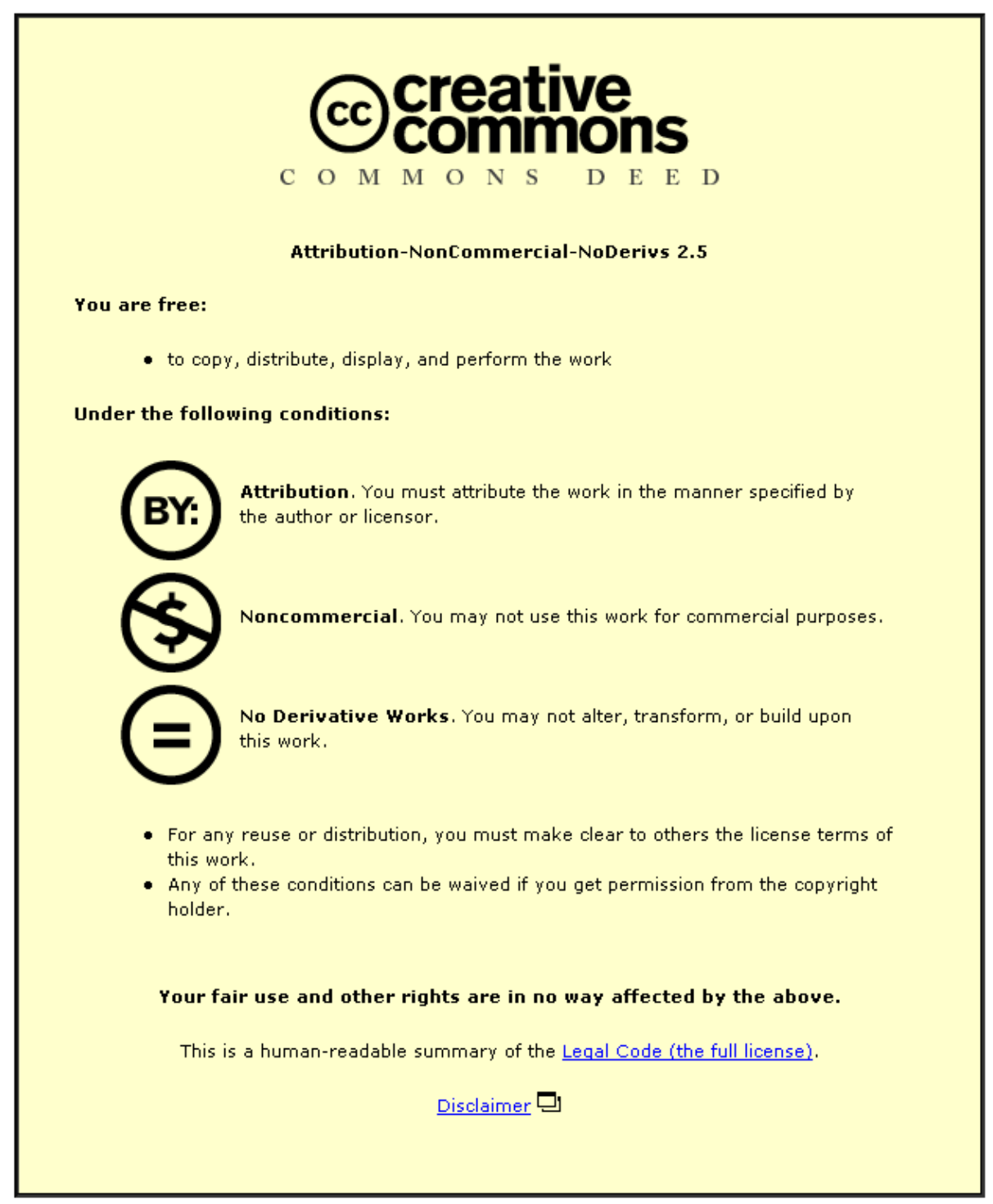

For the full text of this licence, please go to: http://creativecommons.org/licenses/by-nc-nd/2.5/ 


\title{
DAMAGE IN ADHESIVELY BONDED CFRP JOINTS: SINUSOIDAL AND IMPACT FATIGUE
}

\author{
J.P. Casas-Rodriguez, I.A. Ashcroft and V.V. Silberschmidt \\ Wolfson School of Mechanical and Manufacturing Engineering \\ Loughborough University, Leicestershire LE11 3TU
}

\begin{abstract}
The main aim of this paper is to investigate the behaviour of adhesively bonded CFRP joints subjected to cyclic low-velocity impacts and to compare this with fracture in specimens tested in standard fatigue (i.e. non-impacting, constant amplitude, sinusoidal fatigue). It is seen that the accumulated energy associated with damage in impact-fatigue is significantly lower than that associated with similar damage in standard fatigue and that the mechanisms of failure are very different for the two loading regimes. For both types of loading, fracture initiates in the adhesive layer and then propagates into the $0^{\circ}$ ply of the composite adjacent to the adhesive layer. However, the fracture surfaces after impact-fatigue are generally less uniform and exhibit more signs of high rate/brittle fracture than seen in the fracture surfaces after standard fatigue testing. Various parameters are proposed to characterise damage in standard and impact-fatigue and it is shown that crack velocity, accumulated absorbed energy and normalised maximum force are all useful parameters for characterising damage evolution.
\end{abstract}




\section{Introduction}

The use of carbon fibre reinforced polymer (CRFP) in aerospace, automotive and other high performance applications has created the necessity to study the behaviour of this material in fatigue. Records in the time-load histories have shown that these kinds of structures support a variety of cyclic loads that vary through the structure. In some cases, repeated low energy impacts appear in the load spectrum. This phenomenon is known as "impact-fatigue" and it has already been shown that this type of loading can be far more damaging than "standard" fatigue [1] (defined as nonimpacting, constant amplitude fatigue for the purposes of this report).

The main joining methods used in CFRP structures are mechanical fastening and adhesive bonding and the advantages and disadvantages of these techniques have been discussed in [2]. The advantages of adhesive joints include low weight and the potential reduction in stress concentrations. However, concerns with long-term performance under sustained complex loading and the effects of environmental ageing remain.

In the last few decades, researchers have identified the importance of studying the behaviour of fibre reinforced polymeric composites (FRPC) at high strain rates in order to observe the damage and mechanisms of failure in impact conditions. In the laboratory, impact has been commonly simulated using three types of tests. These are: tests with pendulum type machines, where tests rates are below $5 \mathrm{~m} / \mathrm{s}$; drop-weight tests, with rates up to $10 \mathrm{~m} / \mathrm{s}$ and the split Hopkinson pressure bar (SHPB) for rates up to $100 \mathrm{~m} / \mathrm{s}[3]$.

It is well know [4-7] that the interlaminar shear strength of carbon fibre/epoxy composites increases with strain rate. Hosur et al. [4] suggested that this behaviour can be attributed to the time-dependent deformation of the material, which is a product of the visco-elastic behaviour of the matrix in the composite. In addition, they found that even in specimens that do not exhibit failure, the stress-strain behaviour is different after the impact. This has been attributed to the heat generated by the high strains affecting the structure of the matrix material. Further work [5] has shown that the maximum stress supported by the material in one punch impact decreases 
considerably with an increase in the temperature. Hiley et al. [6], however, working with CFRP single lap shear specimens, found no significant differences in the failure surface of samples subjected to quasi-static and impact loads.

Analysis of impact-fatigue in FRPCs has been principally aimed at characterising the reduction in fatigue life as the load is increased. Ray et al. [8], working with a jute/vinyl-ester composite in a cyclic Charpy test, saw increases in the endurance of the material as the impact energy decreased. Some researchers [9, 10] have also identified a threshold energy, below which no visible delamination is seen. Yuan et al. [11] also observed that the response to impact loading depends on the orientation of the fibres in CFRP.

Gomoa et al. [12] compared the performance of PMMA in impact and standard fatigue by testing samples in four-point bending using a SHPB machine. They found that the PMMA was more resistant to crack propagation under impact-fatigue than under standard fatigue with the same maximum force and at quasi-similar strain rates. They also proposed that the critical stress intensity factor is a function of the type of load as well as the load level. Ding et al. [13] investigated the fatigue life of CFRP laminates when combining both sinusoidal loads and an impact. They found that the fatigue strength of the CFRP was affected by the sequence, being more critical in the case when the sinusoidal followed the impact than vice versa.

The behaviour of adhesives under impact has also been studied. Harris and Adams [14], working with a single lap joint in a pendulum impact machine, found little difference between joints tested under impact and quasi-static conditions. In contrast, Beevers and Ellis [15] observed higher strengths in impact loading and suggested this was associated with the strain rate dependence of the adherends. Kihara et al. [16] designed a test to study the response of a thick adherend shear joint subjected to various impact stress waves and observed that the type of fracture was associated with the level of the incident stress. Adams and Harris [17] analysed the block-impact test and concluded that the stress condition in the test is uncertain because of the complex dynamic effects generated by uncertainties in the contact interface between the block and hammer and suggested that the impact-wedge test should be used to measure the impact properties of an adhesive. Blackman et al. [18] also used the impact-wedge 
test and found that results are highly dependent on the environmental conditions. Yokoyama and co-workers $[19,20]$ looked at the impact properties of adhesive joints using SHPB test and found that the tensile strength increased considerably with the loading rate and that this was dependent on the type of adherend used. In addition, they identified an optimum adhesive thickness that was independent of the adherend. Bezemer et al. [3], however, showed that increases in energy absorption at higher strain rates were only seen in some adhesives.

In contrast to the vast body of research into the impact loading of adhesive joints, impact-fatigue has received very little attention to date. In many cases the analysis has been limited to a relatively short series of impacts. Usui and Sakata [21] analysed impact-fatigue in GFRP single lap joints bonded with an epoxy adhesive using a dropweight test. Their results showed that the impact-fatigue strength of the joints was dependent on the magnitude of stress and the loading time. A recent study by CasasRodriguez et al. [1] using single lap joints found significant decreases in the fatigue life when specimens were tested in impact-fatigue, at relatively modest maximum input forces and relatively few cycles, in comparison with standard fatigue. They defined two models to characterise damage in impact-fatigue the modified load-time model and the normalized load-time model.

The current state of research into the impact-fatigue behaviour of adhesive joints using CFRP composites as adherends is characterised by a lack of experimental studies of the many facets of this phenomenon. The main aim of this paper is to investigate the behaviour of bonded CFRP lap-strap joints subjected to cyclic lowvelocity impacts, and to compare this to behaviour in standard fatigue. Various characteristics of the joint response to such loading are presented and some new parameters to characterise the process are introduced. Results from standard fatigue tests are used as a basis for evaluating the danger of neglecting impact-fatigue in the durability analysis of adhesive joints in composites structures.

\section{Experimental setup}

\subsection{Sample preparation}

Samples were manufactured by adhesive bonding cured panels of CFRP. The composite used throughout this study was T800/5245C supplied by Cytec Ltd. The 
matrix, Rigidite 5245C, is a modified bismaleimide/epoxy system and is reinforced with T800 fibres supplied by Toray Industries Ltd. The composite panels were layedup from unidirectional (UD) pre-preg with a volume fraction of 0.6 and thickness of $0.125 \mathrm{~mm}$. A multidirectional (MD) lay-up scheme of $\left[(0 /-45 /+45 / 0)_{2}\right]_{\mathrm{S}}$ was used and the panels were cured for 2 hours at $182{ }^{\circ} \mathrm{C}$ with an initial autoclave pressure of approximately $600 \mathrm{KN} / \mathrm{m}^{2}$. The cured panels were ultrasonically scanned for defects. The material properties for the MD panels are given in Table 1. There were calculated from the UD properties using laminate analysis. The adhesive used was Hysol Dexter's EA9628, which was supplied as a $0.2 \mathrm{~mm}$ thick film. This adhesive is based on diglycidyl ether of bisphenol A with a primary amine curing agent. A reactive liquid polymer, based upon carboxyl terminated butadiene acrylonitrile rubber, was used as a toughening agent.

The lap-strap joints (LSJ) were manufactured using the pre-cured CFRP laminate. The CFRP panels were grit blasted and acetone cleaned prior to bonding. Assembled joints of adhesive and CFRP were cured in an autoclave for $60 \mathrm{~min}$ at $120^{\circ} \mathrm{C}$. The fatigue samples were cut from the bonded panels using a diamond saw. End tabs were bonded to the samples to aid grip in the fatigue tests and to provide load alignment. Holes were drilled in the impact fatigue specimens using 3 different diameters of drill to minimise problems of delamination in the composite. Fig 1 shows the dimensions of the LSJs used in the impact and standard fatigue tests.

Table1

Properties of T800/5245C composite at room temperature.

\begin{tabular}{lccccc}
\hline & $E_{x}(\mathrm{GPa})$ & $E_{y}(\mathrm{GPa})$ & $G_{x y}(\mathrm{GPa})$ & $v_{x y}$ & $v_{y x}$ \\
\hline $\mathrm{UD}$ & 174 & 9.64 & 7 & 0.36 & 0.02 \\
$\mathrm{MD}$ & 99.8 & 28.1 & 25.7 & 0.69 & 0.2 \\
\hline
\end{tabular}




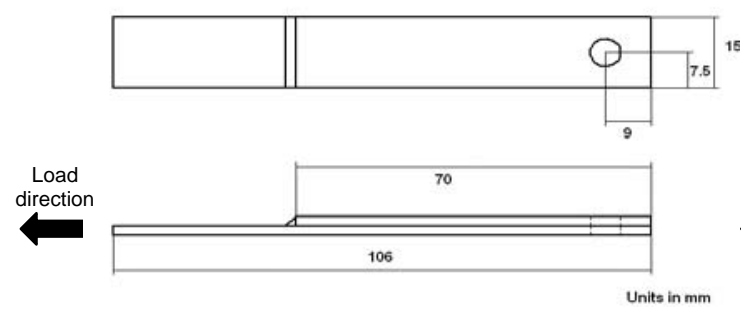

(a)

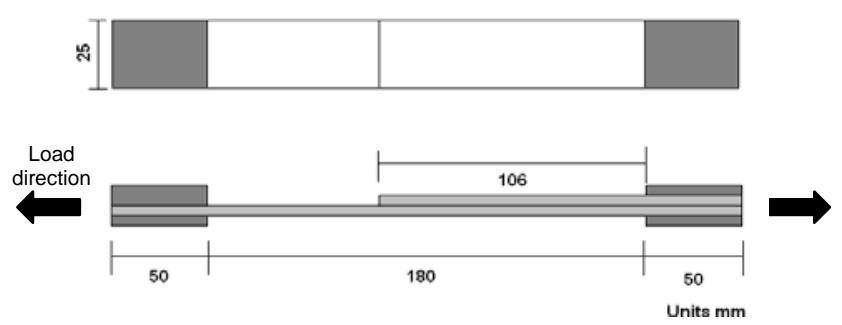

(b)

Fig. 1 Dimensions of lap strap joint specimens: (a) impact-fatigue specimen,

(b) standard fatigue specimen.

\subsection{Impact-Fatigue Tests}

Impact-fatigue was carried out using a modified CEAST RESIL impactor, as described in detail in [1]. The basis of this method is that the specimen is fixed at one end to an instrumented vice and a special impact block is attached to the free end (as shown in Fig 2).

(a)

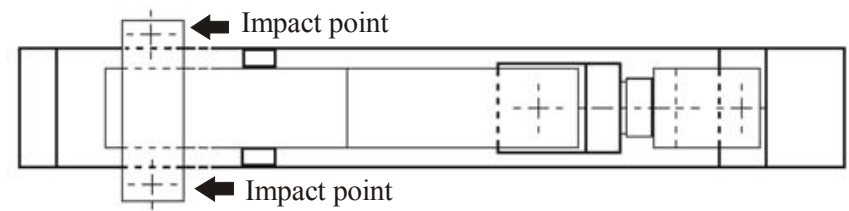

(b)

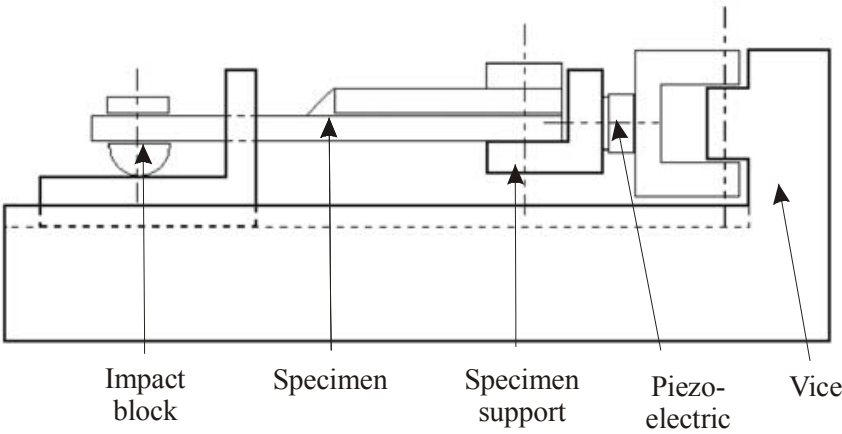

Fig. 2 Sample set-up for impact-fatigue. (a) Plan view, (b) side view. 
In the impact-fatigue test, the pendulum is released from a pre-selected initial angle, which in this case corresponded to a potential energy of $1.07 \mathrm{~J}$ and impacts the specimen at velocity of $1.50 \mathrm{~m} / \mathrm{s}$. These parameters are kept constant during the impact-fatigue test. Changes in the electrical resistance of the piezo-electric sensor are recorded, with a pre-selected sampling frequency of $1000 \mathrm{kHz}$ and up to 3000 data points per cycle. In order to decrease the data noise, a $1 \mathrm{kHz}$ filter was used. The amplified and filtered data was downloaded to a computer as magnitudes of force and time. Typical records of force versus time for two distinct cycles are presented in figure 3. Velocity and energy were calculated from force and time data using equations 1 and 2 respectively. The initial value of velocity was obtained by assuming the conservation of lineal momentum between the hammer and impact block (Fig. 2).

$$
\begin{gathered}
v_{i}=v_{o}-\frac{1}{m} \int_{o}^{i} F \cdot d t \\
E_{i}=\int_{o}^{i} F \cdot v \cdot d t
\end{gathered}
$$

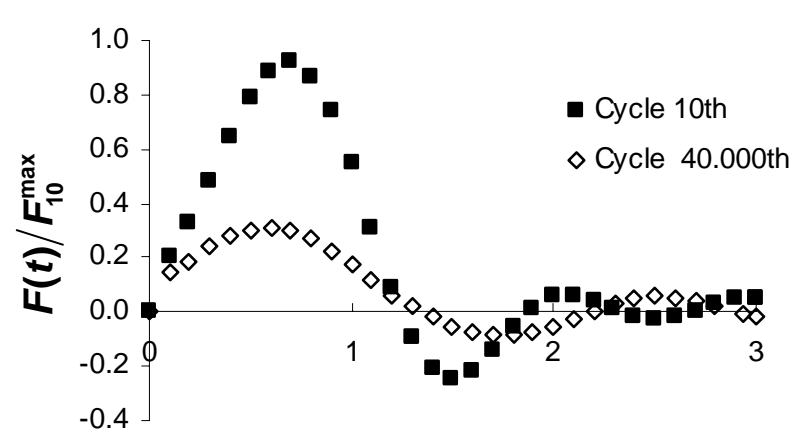

Time [ms]

Fig. 3 Evolution of force in the $10^{\text {th }}$ and $40000^{\text {th }}$ impact.

\subsection{Standard Fatigue}

A servo-hydraulic fatigue testing machine, utilising digital control and data logging, was used in the standard fatigue tests. Testing was in displacement control using a sinusoidal wave, R-ratio (minimum-to-maximum displacement) of 0.1 and frequency of $5 \mathrm{~Hz}$. All testing was in ambient laboratory environmental conditions. Temperature and relative humidity were monitored during the tests and varied 
between $18-25^{\circ} \mathrm{C}$ and $50-60 \%$, respectively. The maximum displacement was selected to generate an initial force that was $56 \%$ of the quasi-static failure load.

\subsection{Fractography}

After testing, both edges of the sample and the fracture surfaces were examined with an optical microscope. In order to retain good resolution over large areas, six pictures were taken over the fracture surface and then merged using Photostitch V 3.1 software. Scanning electron microscopy was used for higher magnification examination of selected fracture surfaces. Specimens were extracted using a diamond saw and gold coated prior to examination.

\section{Results}

\subsection{Standard fatigue}

Analysis of the failure surfaces of specimens loaded in standard fatigue identified three different fracture regions (as shown in Fig. 4). The first region (region I in Fig. 4) corresponds to failure in the adhesive layer. A second region (region II in Fig. 4) is a transition region, in which a mix of failure in the adhesive and in the $0^{\circ}$ ply of the CFRP adjacent to the adhesive is seen. In region III, failure is dominated by fracture in the CFRP ply adjacent to the adhesive. The observed fracture paths are in agreement with previous studies [22].

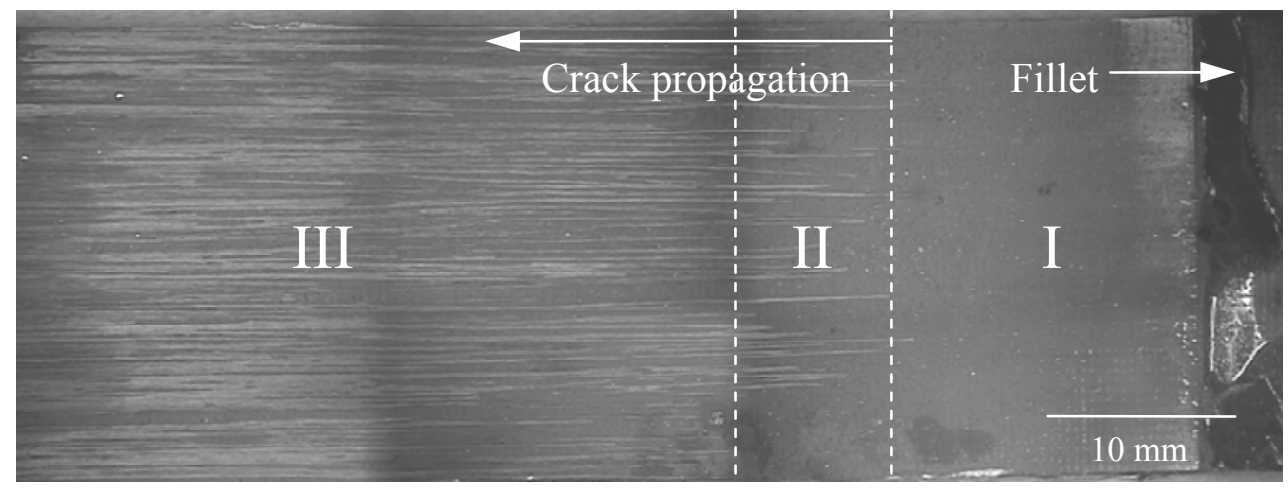

Fig. 4 Failure surface of sample tested in standard fatigue

It should be noted that the lap-strap joint test results in a mixed mode fracture. Johnson [23] described a typical mode ratio $\left(G_{\mathrm{I}} / G_{\mathrm{II}}\right)$ between 0.2 and 0.3 for the LSJ. The mechanism of failure initiation of this type of joint tested in fatigue has been studied previously [24], using both experimental work and finite element analysis. 
The results indicate that the crack initiates in the adhesive at a point near to the embedded corner of the lap adherend (as indicated in Fig. 5). This coincides with the position of a theoretical stress singularity. The 3-dimensional evolution of damage in bonded lap joints is further elucidated in [25]. Here it is shown that cracks will propagate from the singularity in two directions, across the fillet to the free surface and through the adhesive layer towards the adherend/interface and then along the bondline. Furthermore, they found that initiation and propagation is a 3-D mechanism with the crack initiated away from the sample edges and progressing across the sample width until a full through-width crack has developed. This through-width crack is often the first sign of cracking seen in optical examination of damage in the joint and is also the type of crack modelled in 2D analyses. Analysis of principal stresses in the adhesive fillet region suggests that after crack initiation, propagation through the fillet is at an angle of approximately $45^{\circ}$ to the bondline [23]. However, an alternative crack path in which the cracks propagates up the fillet/lap interface for a short distance before propagating through the fillet, is commonly seen in practice, as shown in Fig. 5.

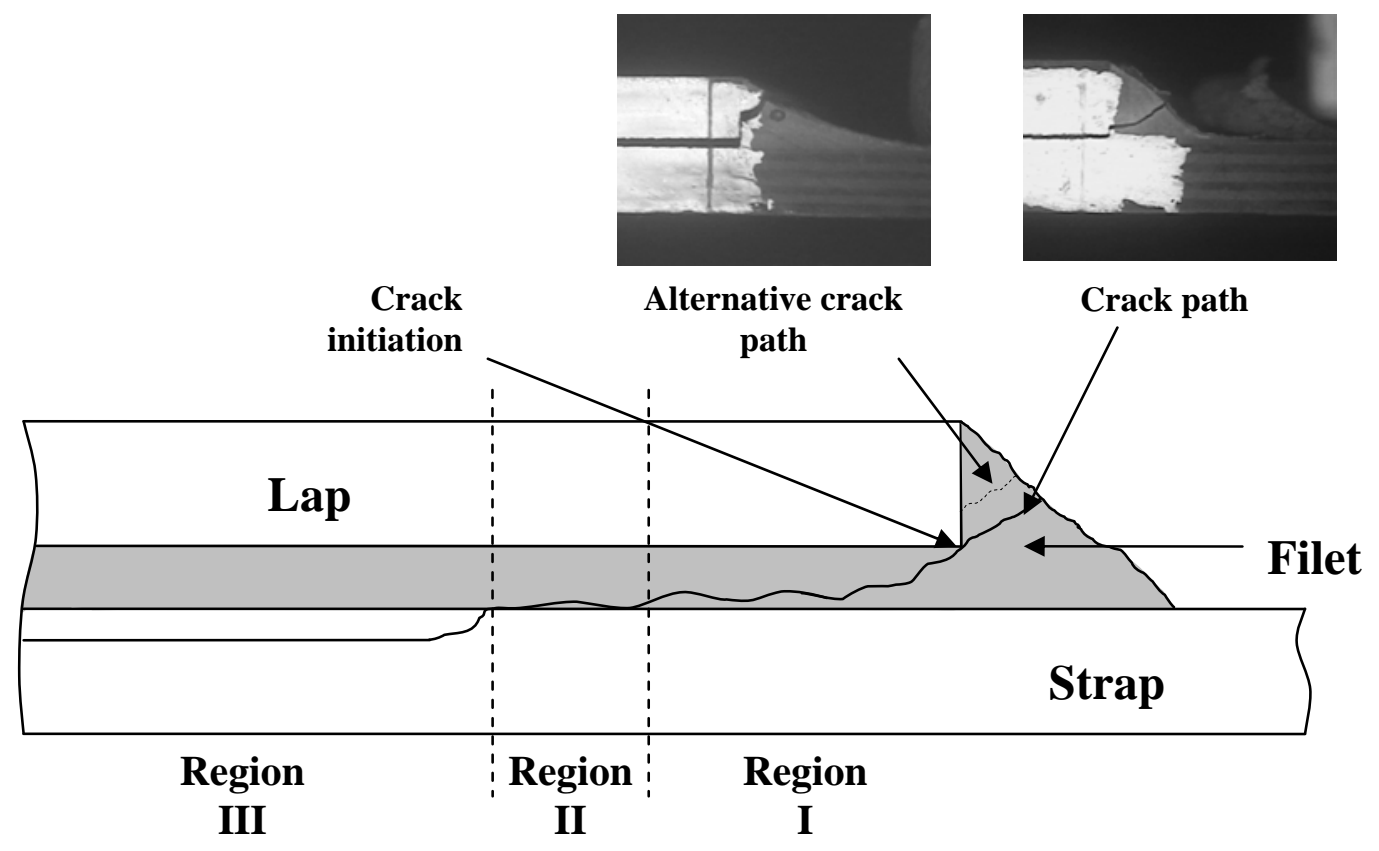

Fig. 5 Crack initiation and propagation in standard fatigue

Scanning electron microscopy (SEM) was used to study the fracture surfaces shown in Fig. 6 in greater detail. In Fig. 6(a) a typical micrograph of fracture in the adhesive (region I failure) is shown. The cohesive-adhesive fracture surface is characterized by 
the presence of flakes that are partly orientated with respect to the direction of the crack growth. Voids with diameter from 1 to $5 \mu \mathrm{m}$ are distributed over the adhesive fracture surface. Previous studies have related these voids with failure in rubbertoughened epoxy adhesives [24] and suggest that these are generated by cavitation of the rubber particles in the strain field ahead of a crack. [26]. Fig. 6(b) shows the transition region (Region II), in which failure both in the adhesive and in the CFRP can be seen. Figs. 6(c) and (d) show region III fracture surfaces, in which failure is predominantly in the $0^{\circ}$ ply of the CFRP adjacent to the adhesive. It can be seen that these is a mix of failure in the matrix and fibre debonding. Shear cusps can be seen in the areas of matrix failure, which are identified with failure mode II fracture [6]. Some fibre breakage is also seen in the fracture surface; however, the main crack front does not break through the fibres and hence remains in the surface of the ply adjacent to the adhesive. Fig. 6 (d) shows the transformation of the cusps to rollers as a consequence of the friction between the surfaces during fatigue.

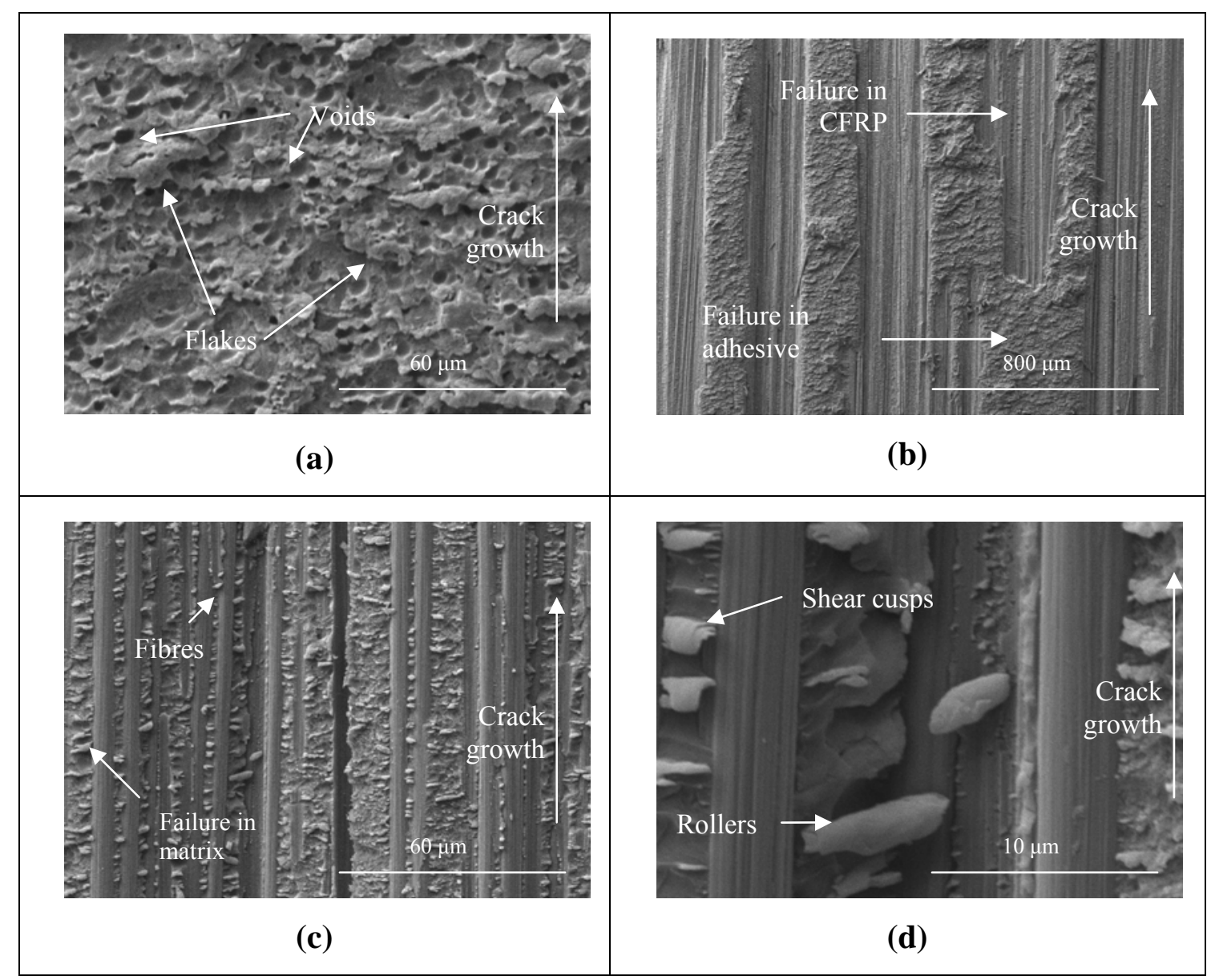

Fig. 6 Scanning electron micrographs of fracture surfaces from samples tested in standard fatigue: (a) Region I, (b) region II, (c) and (d) region III. 
A number of parameters can be calculated from the load-displacement data that is logged during the fatigue tests and in the following section a number of criteria are proposed that can be used to identify changes in the nature of the crack growth and to differentiate between the different mechanisms of failure. The energy absorbed in the $\mathrm{n}^{\text {th }}$ cycle $\left(E_{n}^{*}\right)$ can be used to define the capacity of the joint to absorb energy. It is calculated as the integral of the sum of reaction force and displacement over a cycle:

$$
E_{n}^{*}=\int_{t_{0}}^{t_{f}} F(t) \delta(t) d t
$$

where $F(t)$ describes the force as a function of time and $\delta(t)$ describes the displacement as a function of time. The limits of the integral are defined by the time at the start and finish of a cycle. The accumulated energy absorbed over $N$ cycles $\left(E_{\mathrm{T}}^{*}\right)$ can then be defined as:

$$
E_{\mathrm{T}}^{*}=\sum_{n=1}^{N} E_{n}^{*}
$$

In Fig. 7 the total energy absorbed in creating a unit crack area $\left(E_{\mathrm{T}}^{*} / A_{\mathrm{cr}}\right)$, where $\left(A_{c r}\right)$ is the crack area, is plotted as a function of crack length. By definition this parameter is undefined when the crack area is zero, but can be used when the crack is established. It can be seen in Fig. 7 that $E_{\mathrm{T}}^{*} / A_{c r}$ increases in the early period of the crack propagation that corresponds to region I in Fig. 3. However, at approximately $20 \mathrm{~mm}$ crack growth, there is a sharp discontinuity in the plot. This coincides with the transition from crack growth in the adhesive layer to its growth in the composite. It can also be seen that $E_{\mathrm{T}}^{*} / A_{c r}$ is lower for crack growth in the composite than in the adhesive. 


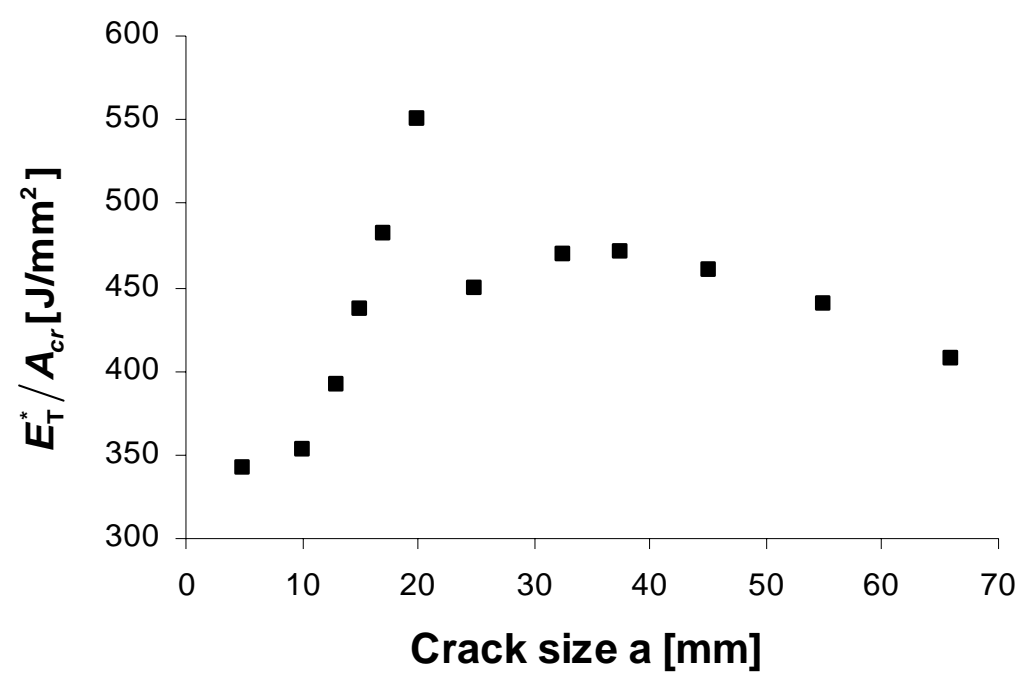

Fig. 7 Changes in the accumulated absorbed energy per unit area with crack length in standard fatigue.

Additional analysis corroborates the observed differences in crack growth in regions I (adhesive failure) and III (matrix-composite failure). Fig. 8 shows changes in the crack growth rate $(d a / d n)$ as the crack develops. It is seen that the crack growth slows in region I and then accelerates in region III. This result is coincident with the changes in $E_{T}^{*} / A_{c r}$ seen in Fig. 7, supporting the hypothesis that increasing levels of absorbed energy are related to lower crack growth rates.

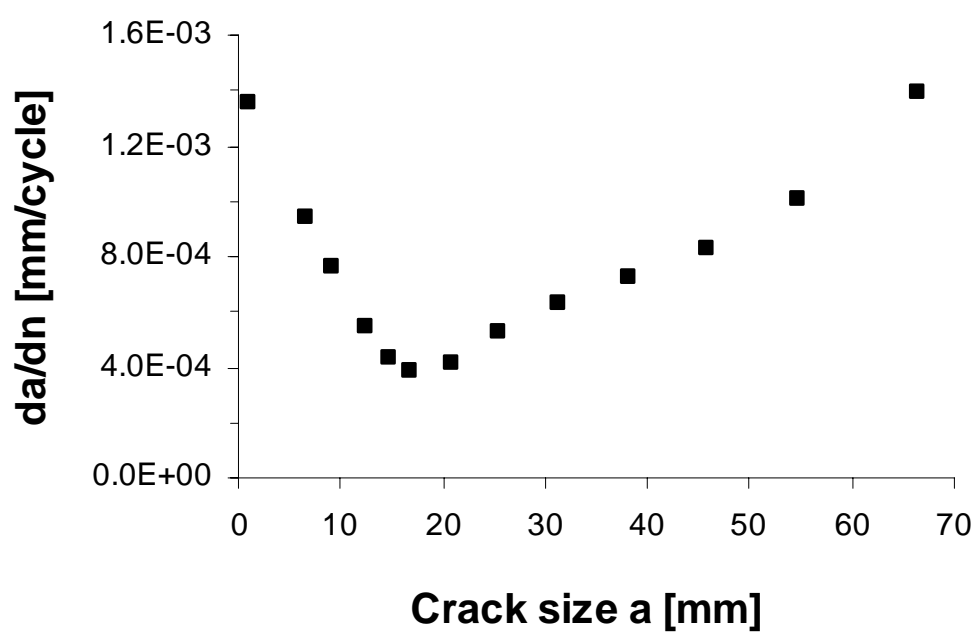

Fig. 8 Changes in the crack propagation rate as a function of crack size in standard fatigue.

\subsection{Impact- fatigue}


On initial optical examination, apparently similar patterns of failure to those described for standard fatigue are also seen in specimens subjected to impact-fatigue (Fig. 9). Again, three regions can be defined. The first region (region A) is defined when crack growth is in the adhesive, a second region (region B) is a transition zone and the third region (region $\mathrm{C}$ ) is defined when the crack growth is the $0^{\circ}$ ply of the composite adjacent to the adhesive layer.

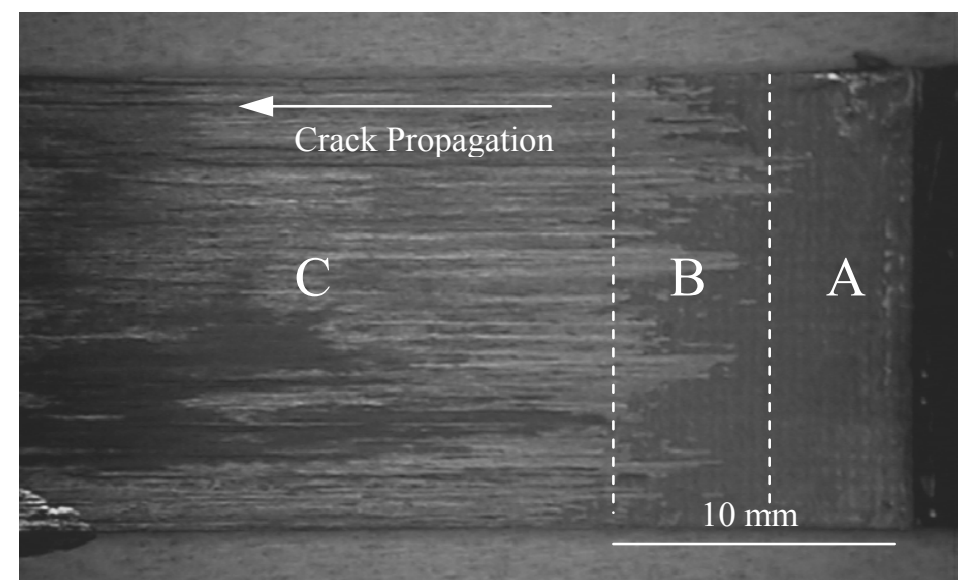

Fig. 9 Failure surface of a sample tested in impact-fatigue

However, analysis by SEM shows that the failure surfaces seen in impact-fatigue are in fact very different to those seen in standard fatigue. Typical fracture surfaces for region A are shown in Figs. 10(a) and (b). It can be seen that the region A fracture surface from impact fatigue differ significantly from the region I fracture surface seen after standard fatigue. The fracture surface is less uniform and there are signs of multiple damage initiation and termination sites. In some areas of the fracture surface the impression of fibres can be seen indicating that some of the damage is occurring close to or in the composite. The voids and flakes seen in region I of the standard fatigue fracture surface are also less evident. The lack of voids, which have been attributed to cavitation of the rubber toughening particles, is in agreement with the work of Takeshi [27]. He observed that the generation of voids in the adhesive was dependent on the crack speed, relating fast crack growth with low void generation. This phenomenon was related to the relationship between high crack growth and low plastic deformation. Micrographs from region $\mathrm{C}$ of the impact-fatigue fracture surface can be seen in Figs. 10(c) and (d). It can be seen that fracture of fibres is far more common than in the standard fatigue fracture surface. Also, as with the adhesive 
failure in impact-fatigue, the fracture surface is less uniform than that for standard fatigue and shows signs of multiple damage events. Fracture in the composite matrix can be more clearly observed in Figs. 10(e) and (f). As in standard fatigue, shear cusps can be seen; however, these are more randomly distributed and no longer appear to be related to the crack propagation rate. Also, the matrix fracture exhibits more brittle behaviour, as seen in Fig. 10(f). Overall, it can be said then that fracture surfaces after impact-fatigue are less uniform than those after standard fatigue, with multiple crack fronts, varying crack depth and non-uniform crack front development. They also exhibit more features associated with brittle and mode I fracture.

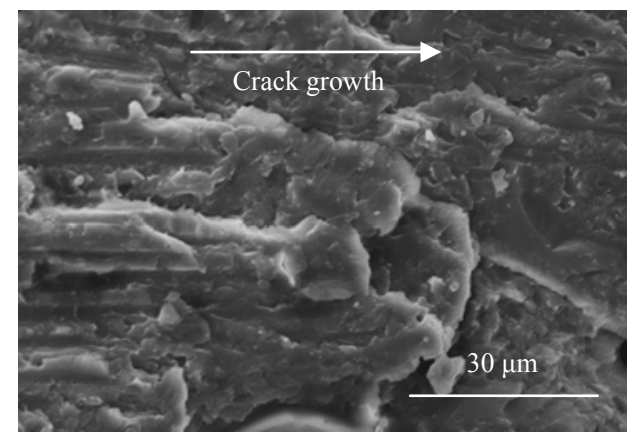

(a)

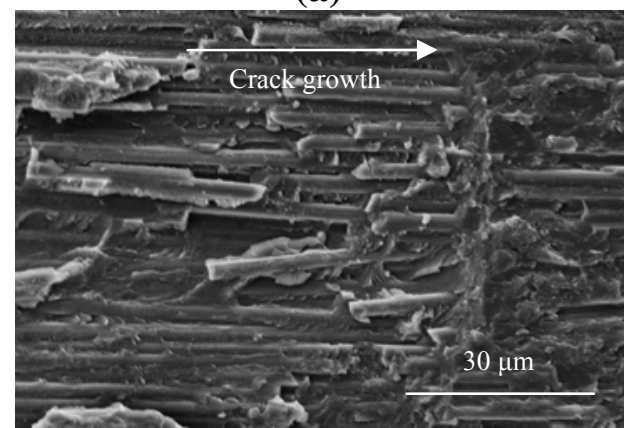

(c)

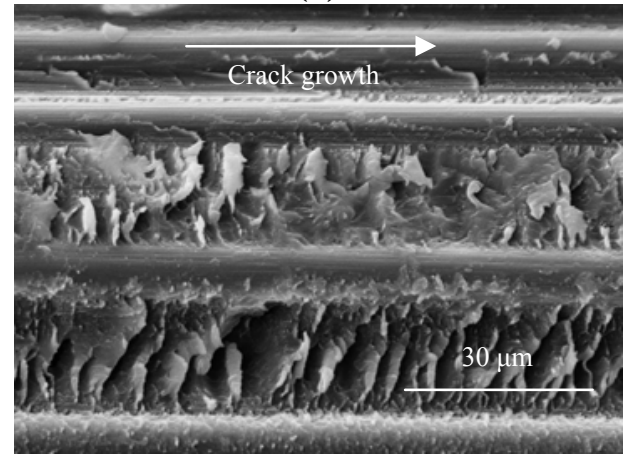

(e)

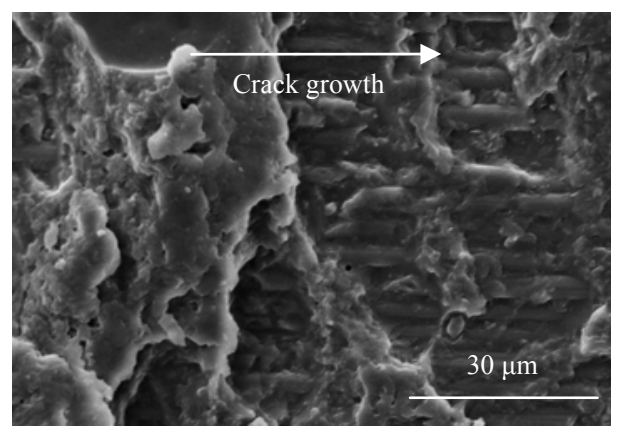

(b)

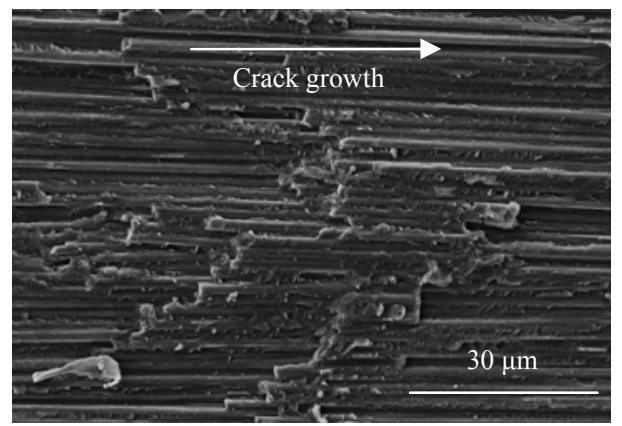

(d)

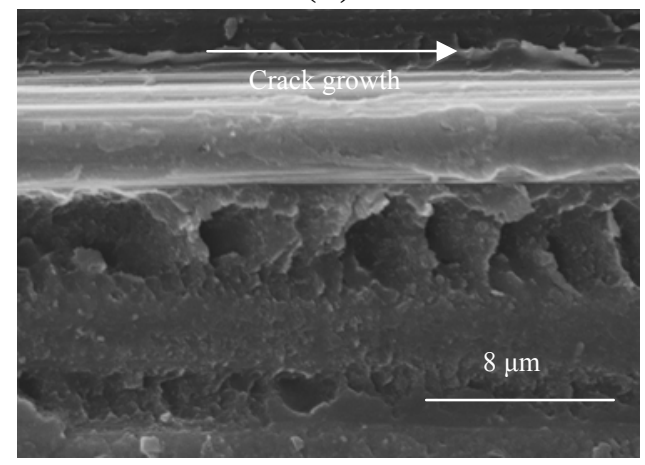

(f)

Fig. 10 Scanning electron micrographs of fracture surfaces from samples tested in impact-fatigue: (a) and (b) region $\mathrm{A},(\mathrm{c})$ - (f) region $\mathrm{C}$. 
As with standard fatigue, various parameters can be calculated from the data collected during the impact-fatigue tests in order to characterise the failure process. One parameter that can be used to characterise impact-fatigue is the maximum force reached in the $n^{\text {th }}$ cycles, $F_{n}^{\max }$. This can be normalised with respect to the maximum force measured in the $10^{\text {th }}$ cycle in order to obtain a criterion that can be used to detect crack initiation. The $10^{\text {th }}$ cycle is selected rather the $1^{\text {st }}$ cycle as the normalising parameter in order to avoid possible problems with misalignment in the initial stages of the fatigue life. In Fig. 11 it can be seen that stable behaviour was detected for the first 1000 cycles, after which a dramatic change was detected. This change is identified as a phase of crack initiation in the joint. After the $3000^{\text {th }}$ cycle the normalized maximum force becomes practically constant, albeit with a large degree of scatter that is consistent with the non-uniform fracture surfaces. This part of the plot corresponds to region $\mathrm{C}$ of the fracture surface, as identified in Fig. 9.

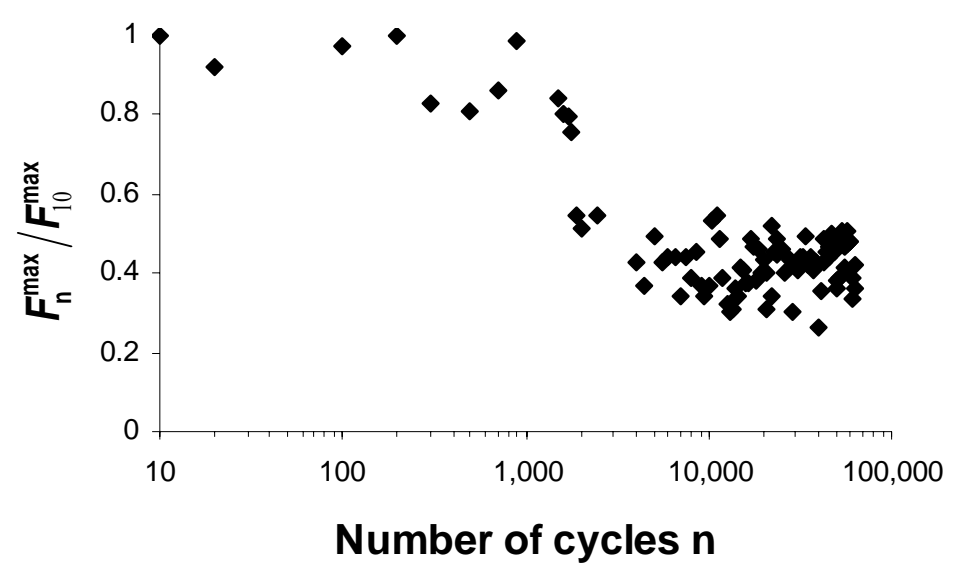

Fig. 11 Changes in the normalised maximum force during crack growth in impactfatigue

An alternative parameter that can be used to identify changes in the crack growth mechanism is the accumulated energy over the $n^{\text {th }}$ cycle, $E_{n}^{*}$, as already defined in Eqn. 2 for impact and Eqn. 3 for standard conditions. In the case of impact-fatigue this can be normalized with respect to the initial potential energy of the hammer, $E_{0}$. This is plotted as a function of cycles in Fig. 12. It can be seen that below 1000 cycles there is quasi-constant behaviour. However, $E_{n}^{*} / E_{0}$ decreases rapidly between 1000 and 3000 cycles, which is consistent with the onset of macro-damage propagation in 
the joint. Above 3000 cycles there is quasi-constant behaviour with a large degree of scatter, which can be related to region $\mathrm{C}$ fracture. It should be noted that the difference between $E_{0}$ and $E_{n}^{*}$ cannot be used to directly calculate the energy used in creating the new fracture surfaces because of additional sources of energy dissipation in the system. In spite of this, the difference between $E_{0}$ and $E_{n}^{*}$ can still be used as a useful reference value of the energy associated with crack growth. as this is considered the principal source of energy consumption.

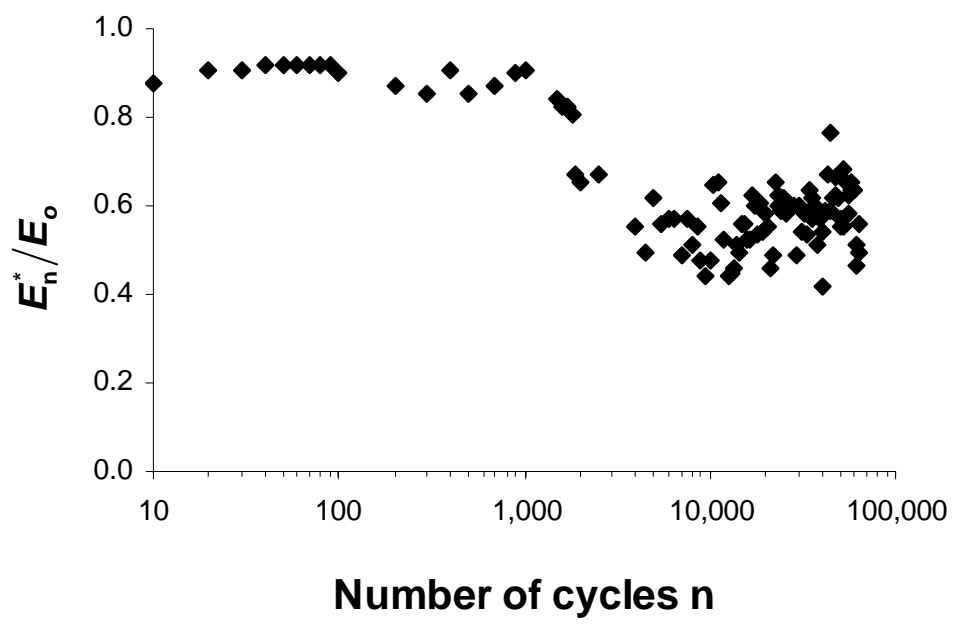

Fig. 12 Changes in absorbed energy during crack growth in impact-fatigue

\subsection{Comparison of impact-fatigue and standard fatigue}

Differences in crack area evolution in standard and impact fatigue are compared in Fig. 13, using the number of cycles to failure as the index of comparison. The results show that impact-fatigue is characterized by two principal tendencies; fast crack growth in the early fatigue life, i.e. less than 10.000 cycles, followed by slow crack propagation. Unfortunately, precise details of crack growth in the fast fracture stage have not been captured to date. Standard fatigue shows an initiation period followed by an acceleration phase. After this there is quasi-constant propagation until a second acceleration phase is reached. Initial measurements indicate crack growth in the early stages of impact-fatigue in excess of $2.4 \times 10^{-3} \mathrm{~mm} /$ cycle. In contrast, the maximum crack speed measured for the initial $20 \mathrm{~mm}$ of crack growth in standard fatigue was approximately $1.4 \times 10^{-3} \mathrm{~mm} /$ cycle. 


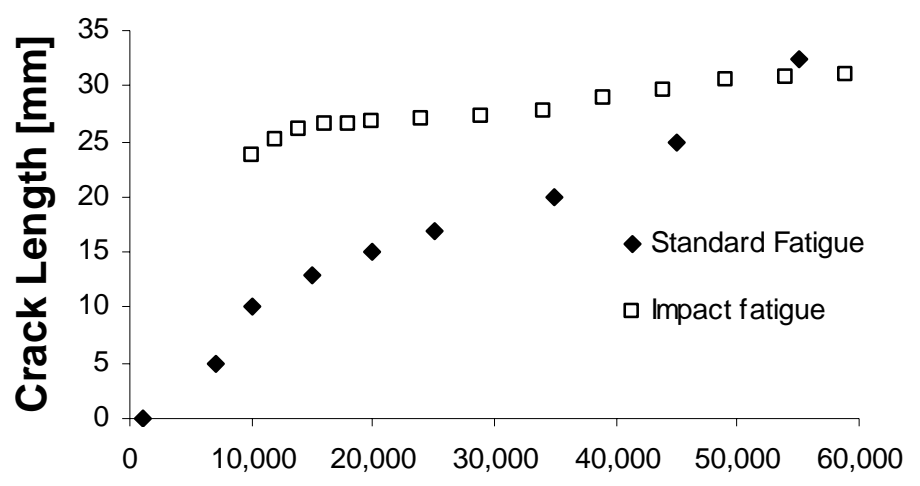

\section{Number of cycles $\mathbf{n}$}

Fig. 13 Crack propagation in impact-fatigue and standard fatigue

Comparison of $E_{\mathrm{T}}^{*}$ against crack area $\mathrm{A}_{\mathrm{cr}}$ for standard fatigue and impact-fatigue can be seen in Fig. 14. It is obvious that damage is generated under impact-fatigue conditions under significantly lower energy levels that required for similar damage in standard fatigue.

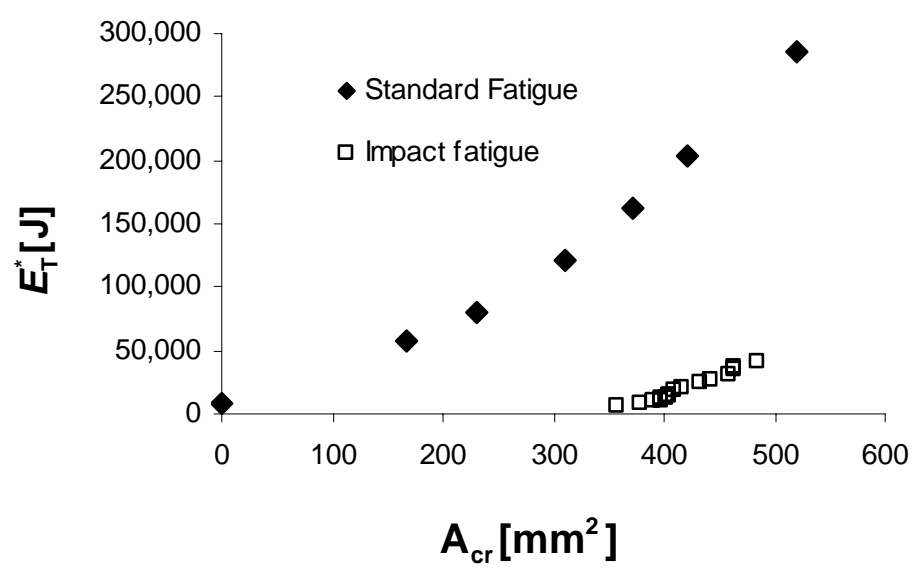

Fig 14 Comparison of accumulated energy as a function of damage in impact-fatigue and standard fatigue

\section{Conclusions}

The behaviour of adhesively bonded composite lap joints subjected to repetitive low velocity impacts (impact-fatigue) and standard constant amplitude fatigue has been analysed and compared in this paper. Macroscopic analysis of the crack growth has shown that for both types of loading, failure initiates in the adhesive layer and then propagates into the $0^{\circ}$ ply of the CFRP adjacent to the adhesive layer. However, higher-magnification examination of the fracture surfaces shows that the failure 
mechanisms involved in impact-fatigue are very different to those in standard fatigue. In the adhesive failure region there is extensive voiding and the formation of regular flakes oriented with respect to the direction of crack growth after standard fatigue. However, in the corresponding region after impact-fatigue the flakes are less regular, the voids are not present, the crack depth varies more and there are signs of multiple damage initiation and arrest events. In standard fatigue, fracture in the composite failure region is dominated by regular shear cusps and matrix rollers in the matrix failure areas and fibre debonding. After impact-fatigue the composite failure region is less uniform, with higher incidence of fibre breakage and a more brittle appearance to the matrix failure areas.

It has been shown that the maximum force reached in the $n^{\text {th }}$ cycle $\left(F_{n}^{\max }\right)$ and the accumulated energy over the $n^{\text {th }}$ cycle $\left(E_{n}^{*}\right)$ can be used as criteria for damage characterisation. The scatter seen in these parameters for crack growth in impactfatigue can be related to the non-uniform appearance of the fracture surfaces.

It has been shown that crack propagation rates tend to be higher in impact- fatigue and that damage occurs at significantly lower energy levels than that required for similar damage in standard fatigue. This reinforces the view proposed previously [1] that impact-fatigue is a potentially dangerous form of loading, both for adhesives and polymer composite materials

\section{References}

1. Casas-Rodriguez J.P., Ashcroft, I.A., Silberschmidt V.V., Damage evolution in adhesive joints subjected to impact fatigue, Int. J. Sound Vib., in press.

2. Schön J., Starikov R., Fatigue of joints in composites structures. Fatigue in Composites, ed. Harrys B., Woodhead Publishing Limited, 2000: 621-643

3. Bezemer A.A., Guyt C.B., Vlot A., New impact specimen for adhesive: optimization of high-speed-loaded adhesive joints. Int. J. Adh. Adhes.. 1998; 18:255260 
4. Hosur M.V. Waliul Islam S.M. Vaidya U.K., Kumar A., Dutta P.K., Jeelani S., Dynamic punch shear characterization of plain weave graphite/epoxy composites at room and elevated temperatures. Comp. Struct. 2005; 70:295-307

5. Hosur M.V. Waliul Islam S.M. Vaidya U.K., Dutta P.K., Jeelani S., Experimental studies on the punch shear characterization of satin weave graphite/epoxy composite at room and elevated temperatures. Mater. Sci. Engng. 2004; A368:269-279

6. Hiley M.J., Dong L., Harding J., Effect of strain rate on the fracture process in interlaminar shear specimens of carbon fibre-reinforced laminates. Comp. A. 1997; 28A:171-180

7. Lifshitz J.M., Leber H., Response of fibre-reinforced polymers to high strain-rate loading in interlaminar tension and combined tension/shear. Comp. Sci. Technol.. 1998; 58: 987-996

8. Ray D., Sarkar B.K., Bose N.R., Impact fatigue behaviour of vinylester resin matrix composites reinforced with alkali treated jute fibres. Comp. A. 2002; 33: 233-241

9. Khan B., Rao R.M.V.G.K, Venkataraman N. Low velocity impact fatigue studies on glass epoxy composite laminates with varied material and test parameters - effect of incident energy and fibre volume fraction. J. Reinf. Plast. Comp. 1994; 14:1150-1159

10. Sinmmazçelik T., Armağan A., Impact-fatigue behaviour of unidirectional carbon fibre reinforced polyetherimide (PEI) composites. J. Mat. Sci. A 2006; Published online

11. Yuan Q., Friedrich K., Karger-Kocsis J., Low-energy charpy impact of interleaved CF/EP laminates. Appl. Comp. Mater. 1995; 2:119-133

12. Gomaa A.I., Hamdy A.H., Moet A., Subcritical crack propagation under cyclic stress impulse. Int. J. Fract. 1992; 53: 187-192 
13. Ding Y.Q., Yan Y., McIlhager R., Effect of impact and fatigue loads on the strength of plain weave carbon-epoxy composites. J. Mater. Proc. Tech. 1995; 55:5862

14. Harris J.A., Adams R.D., An assessment of the impact performance of bonded joints for use in high energy absorbing structures. Proc. Inst. Mech. Engrs. 1985; 199: $121-131$

15. Beevers A., Ellis M.D., Impact behaviour of bonded mild steel lap joints. Int. J. Adh. Adhes.. 1984; 4(1): 13-16

16. Kihara K., Isono H, Yamabe H. and Sugibayashi T. A study and evaluation of the shear strength of adhesive layers subjected to impact loads. Int. J. Adh. Adhes.. 2003; 23: $253-259$

17. Adams R.D., Harris J.A. A critical assessment of the block impact test for measuring the impact strength of adhesive bonds. Int. J. Adh. Adhes.. 1996; 16: 61-71

18. Blackman B.R.K., Kinloch A.J., Taylor A.C., Wang Y., The impact wedge peel performance of structural adhesives. J. Mater. Sci. 2000; 35: 1867-1884

19. Yokoyama T. Experimental determination of impact tensile properties of adhesive butt joints with the split Hopkinson bar. J. Strain Anal.. 2003; 38(3): 233-245

20. Yokoyama T., Smitzu H., Evaluation of impact shear strength of adhesive joints with the split Hopkinson bar. JSME Int. J. Series A. 1998; 41(4): 503-509

21. Usui Y, Sakata O., Impact-fatigue strength of adhesive joints. Jap. Soc. Prec. Eng. $1984 ; 18(3): 213-218$

22. Ashcroft I.A., A simple model to predict crack growth in bonded joints and laminates under variable-amplitude fatigue. J. Strain Anal. 2004; 39(6 ): 707-716

23. Johnson, W.S., Stress analysis of the cracked lap shear specimen: An ASTM 
Round-Robin, J. Test. Eval. 1987; 15(6): 303-324.

24. Ashcroft I. A., Abdel Wahab M.M., Crocombe A.D, Hughes D.J., Shaw S.J., The effect of environmental on the fatigue of bonded composite joints Part1: testing and fractography. Comp. A. 2001; 32: 45-58

25. Hua Y. Abdel Wahab M.M., Crocombe A.D, Ashcroft I. A. Modelling environmental in EA9321-bonded joints using a progressive damage failure model. J. Adh. 2006; 82:135-160

26. Little M. S.G., The durability of structural adhesive joints. PhD thesis, Imperial College of Science, London, 1999

27. Takeshi O., The fatigue behaviour of toughened epoxy polymers. $\mathrm{PhD}$ thesis, Imperial College of Science, London, 1999

28. Abdel Wahab M.M., Ashcroft I.A., Crocombe A.D., Prediction of fatigue thresholds in adhesively bonded joints using damage mechanis and fracture mechanics. J. Adhesion Sci. Technol. 2001; 15(7): 763-781 